\title{
Supervision and control by SCADA of an automated fire system
}

\author{
Omar Chamorro-Atalaya, Dora Arce-Santillan, Teodoro Diaz-Leyva, Martin Diaz-Choque \\ Faculty of Engineering and Management, National Technological University of Lima Sur (UNTELS), \\ Villa El Salvador, Perú
}

\begin{tabular}{l}
\hline \hline Article Info \\
\hline Article history: \\
Received May 23, 2020 \\
Revised Jul 28, 2020 \\
Accepted Aug 8, 2020 \\
\hline Keywords: \\
Automated control \\
Open protocol communication \\
Programmable logic controller \\
Scada \\
Sprayer \\
Supervision \\
Variable frequency drive
\end{tabular}

\begin{abstract}
The purpose of this article is to describe the development of a prototype of a monitoring and control system for a fire-fighting system, implemented through SCADA (supervisory control and data acquisition) for which the OPC (OLE for process control) is known. Known KepServerEX6 (single data source connectivity platform), with which the integration of the PLC (programmable logic controller), the human-machine interface (HMI) and the computer will be controlled, with the application of monitoring the operating parameters of a fire fighting system. These parameters are the pressure and flow of the electric pump, the values of the parameters are regularly controlled automatically by means of a frequency variator, according to the sprinkler actuation, the variator varies its operating frequency until achieving the optimal pressure and flow values. The level of correlation between the indicators to be monitored by the SCADA system is highly significant, equal to $0.977,0.983$ and 0.997 respectively. In addition, the dispersion model of the indicators monitored by the SCADA system will be determined, is the quadratic, with a determination factor of 0.999 .
\end{abstract}

This is an open access article under the CC BY-SA license.

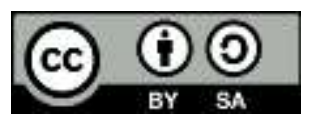

\section{Corresponding Author:}

Omar Freddy Chamorro Atalaya

Av. Central y Av. Bolivar

Sector 3, Grupo 1A - 03, Villa El Salvador, Peru

Email: omar_chamorro1@ hotmail.com

\section{INTRODUCTION}

Every organization where people work is exposed to the presence of risks, conditioned by the environment in which its activities are carried out [1]. In case of not being controlled these risks can be triggered by accidents and damage to property, which can be caused by natural effects or by acciodentes of people as part of their routine activities [2]. From the field of research, development and innovation and taking into account the evolution of technology, there are various electronic solutions that improve conditions in terms of security and fire protection in companies [3]. The risk of fire and explosion are two of the most important risks that must be controlled in the workplace. Electronic systems reduce response time to emergencies [4].

In the industry there are vital systems and equipment to keep the company's production process active, ensuring the availability and operation of all the emergency equipment present in the facilities [5]. To guarantee operational continuity in vital critical process and industrial safety equipment, a system is required to monitor the operating and operational parameters of the fire protection system [6]. A fire protection system is essential in all types of industrial warehouses, companies or buildings to safeguard human lives and minimize the economic losses caused by fire [7]. To determine the necessary prevention and protection measures that help reduce the risk of fire in buildings, the degree of risk must be evaluated [8]. It is important in this type of project to monitor and control the project from the beginning of the design to the operation and maintenance of the system, [9] defining the quality control mechanisms, the operational tests and the 
procedures that must be carried out for its correct operation ensuring that its pressure and flow indicators are adequate permanently [10]. In the case of underdeveloped countries that often do not have the economic resources necessary to invest in high-tech fire systems, which are usually very expensive and their function is only to protect, they make industries ignore this type of systems, the same that would harbor a high risk for the life of the workers [11]. For this reason, technology motivates companies to apply methodologies to control their processes [12].

The control and supervision in real time of a process is carried out through a control system called SCADA [13] which has hardware and software components that allow to supervise and control the industrial process [14]. This system monitors the process data for further processing and provides a communication interface between the user and the machine [15]. Process supervision generally refers to decision-making activities aimed at maintaining the functioning of the system [16]. The SCADA control system refers to control, supervision and data acquisition that allows the management and control of any local or remote system thanks to a graphical interface that communicates the user with the system [17]. A SCADA system is an application or set of software applications specially designed to work on production control computers, with access to the plant through digital communication with instruments and actuators, and a high-level graphic interface for the operator (touch screens, mice or cursors, styluses, etc.) [18]. It has the benefits of reducing engineering costs, time and risk through easy integration with all devices in the plant [19].

In order to integrate the SCADA system with the other components of the automated process, an OPC is used, which allows interoperability for the safe and reliable exchange of information in the space of industrial automation and in other industries [20]. It is used to ensure a continuous flow of information and overcome communication problems between controller devices or applications from multiple providers [21]. Also, the human machine interface (HMI), are used to represent the reality of processes [22]. The OPC standard is based on a series of specifications developed by industry vendors, end users and software developers and managed by the OPC that serve to define the interface between clients and servers, real-time data access, alarm monitoring and events, access to history among other applications [23]. OPC Servers are bi-directional connectors that allow you to "read from" and "write to" a Data source [24]. The relationship between the OPC Server and the OPC Client is of the master/slave type, which means that an OPC Server will only transfer data from/to a Data Source if an OPC Client requests it [25].

In this sense, the purpose of this article is to describe the development of a monitoring and control system implemented through SCADA, by using the OPC KepServerEX6, with which the integration of the programmable logic controller, the human-machine interface (HMI) will be achieved. And the computer, in order to monitor and control the parameters of a fire-fighting system, which is automated by means of a PLC; these parameters to control are the pressure and flow of the pump, when the sprinklers are activated.

\section{PROCEDURE}

In order to control and supervise the operating parameters (pressure and flow) of the fire fighting system, implemented for an industrial warehouse, initially as a prototype, the architecture outlining the components is specified in Figure 1 of the industrial network.

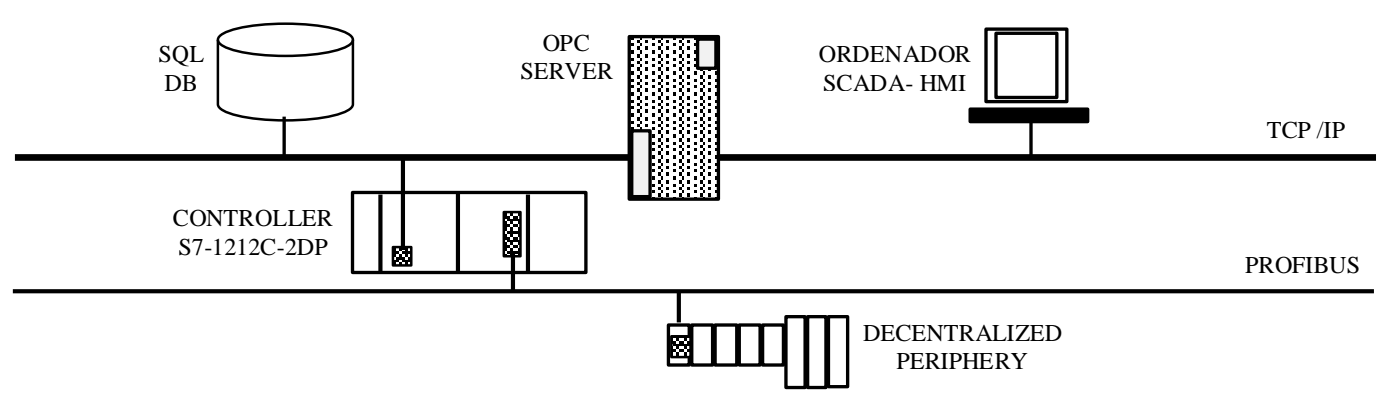

Figure 1. Network architecture of the control and supervision system of the fire fighting system

Established the network architecture of the components that allow the supervision and control of the operating parameters of the fire fighting system, the procedure for programming the programmable logic controller and SCADA is shown Figure 2. 
Initially, a variable table is created in which analog (0-10 volts) digital inputs (Boolean type) and digital outputs (Boolean type) are specified in the programmable logic controller register. Once the input and output variables are specified, programming is carried out in the PLC so that synergy is established between all the components that participate in the fire fighting system for monitoring and supervision. In Figure 2, the first segment of the programming of the fire system automation is shown, in which a block (type SR) called system (M0.0) is created in which a start button (start) is connected to the SET input and at the REST input, a normally closed (NC) button is connected, which is denially called ina stop, and at the output of the SR (Set Rest) block, a digital output Q0.3 is connected, indicating that the system is found on or off. One of the NA (normally open) contacts of the system block (M0.0) is in series with all the segments of the program in order to control them.

Figure 3 shows the programming the frequency variator who will regulate the operation speed of the electric pump, which requires the use of 3 speeds (low, medium, high), which the PLC will control the variator (simatic V20). Furthermore, sensor 1 (I0.2), sensor 2 (I0.3) and sensor 3 (I0.4) are in parallel and all of them in series with the NC contacts (normally closed) of the average speeds (M0.3), high (M0.4) and with the NO contact of the system (M0.0), which control the switching on and off of the low speed (M0.2) and the hmi pump (M0.1).

Figure 4 shows the programming of the on and off of the lighting and outlet outputs. In the third segment of this programming, the NO contacts of solenoid valves $1(\mathrm{Q} 0.0), 2(\mathrm{Q} 0.1)$ and $3(\mathrm{Q} 0.2)$ are shown in series with the NO contact of the system (M0.0), the which control the lighting output (Q0.4) and outlet (Q0.5).

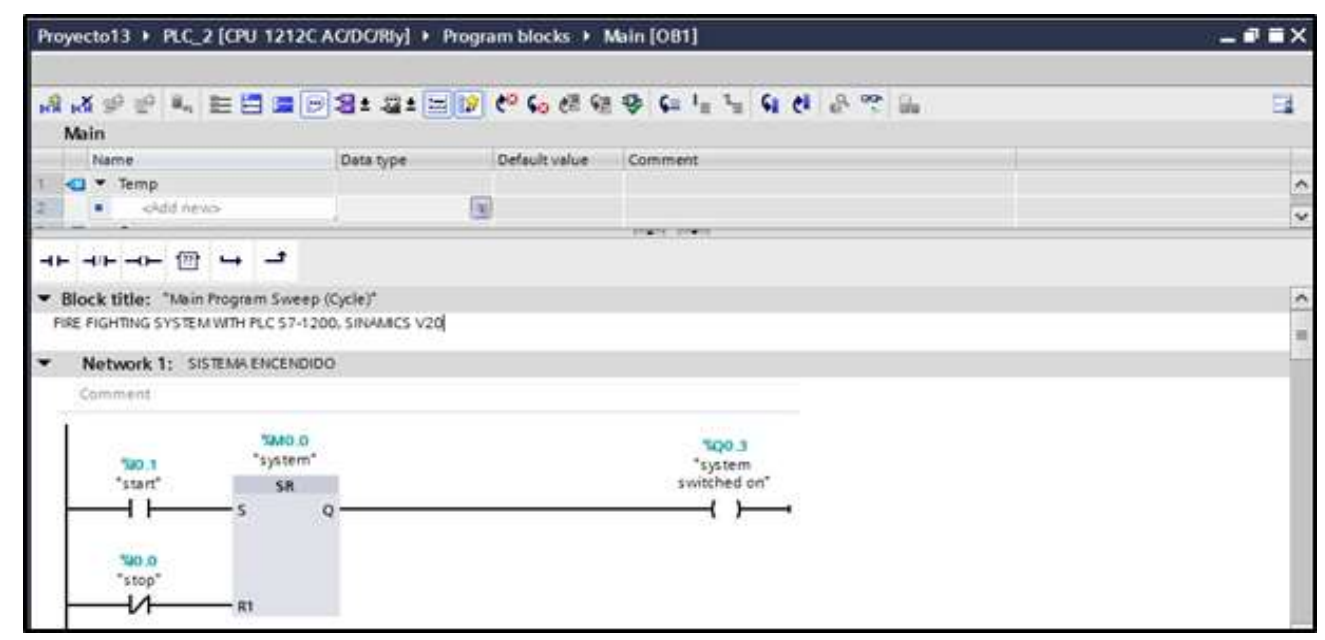

Figure 2. Ignition system programming

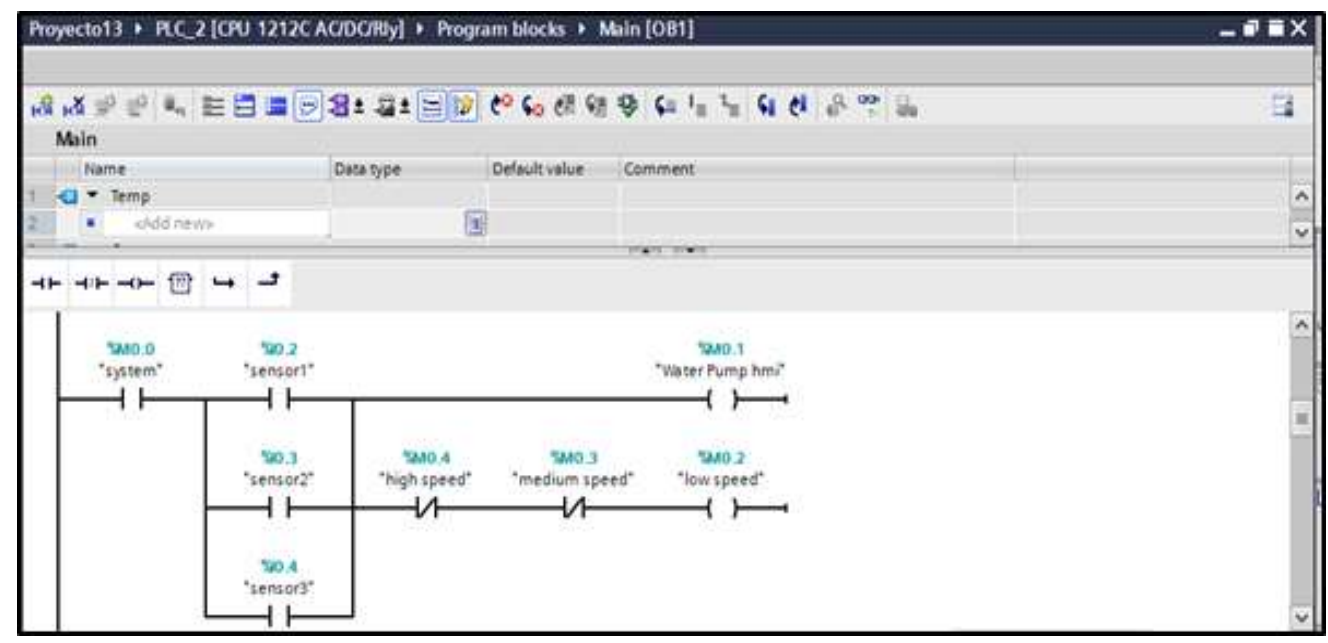

Figure 3. Programming the frequency inverter speeds 
In Figure 5, the alarm programming is carried out, in this function block, the warning alarms are found, it is observed in segment 1 that sensor 1 (I0.2) is in series with the data blocks_1 of sensors 1 and 2 (DB1.DBX0.3), 1 and 3 (DB1.DBX0.4), 1 and 2 and 3 (DB1.DBX0.6), the same ones that allow the control of the output of data block_1 Sensor 1 (DB1.DBX0.0). Sensor 2 (I0.3) is in series with data blocks_1 of sensors 1 and 2 (DB1.DBX0.3), 2 and 3 (DB1.DBX0.5), 1 and 2 and 3 (DB1. DBX0.6), which control the output of data block_1 of sensor 2 (DB1.DBX0.1). Sensor 3 (I0.4) is in series with data blocks_1 of sensors 1 and 3 (DB1.DBX0.4), 2 and 3 (DB1.DBX0.5), 1 and 2 and 3 (DB1. DBX0.6), which control the output of data block_1 of sensor 3 (DB1.DBX0.2).

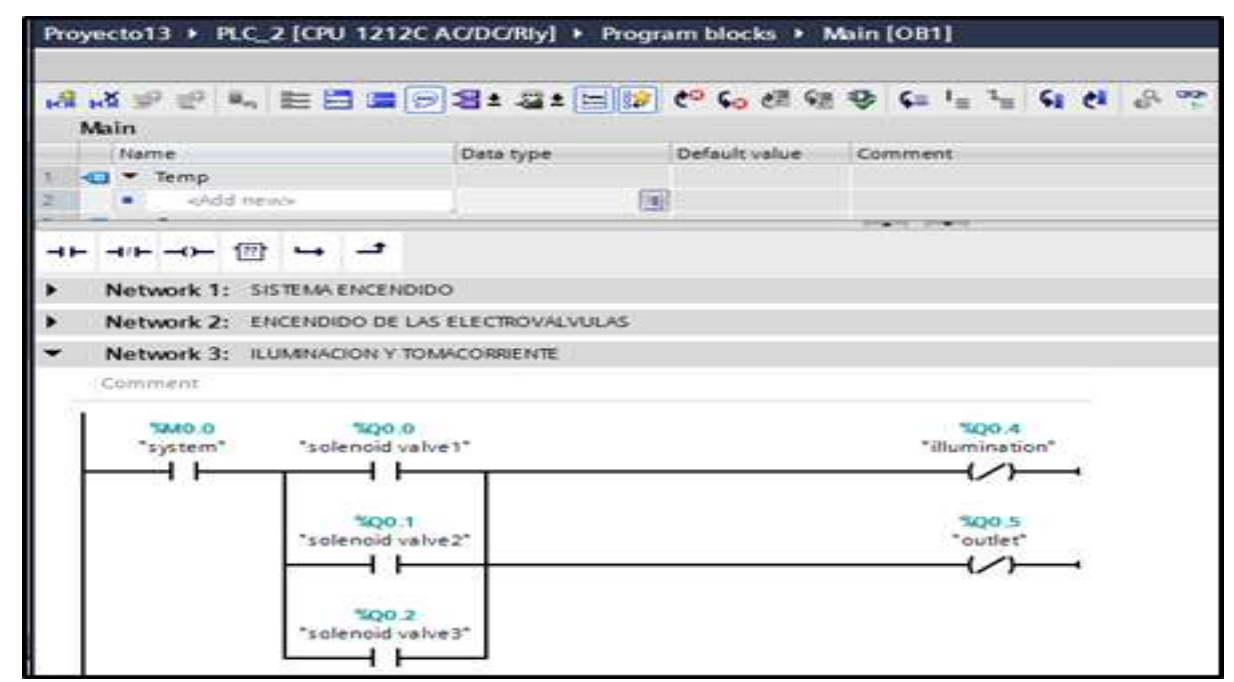

Figure 4. Programming the lighting on and off and outlets

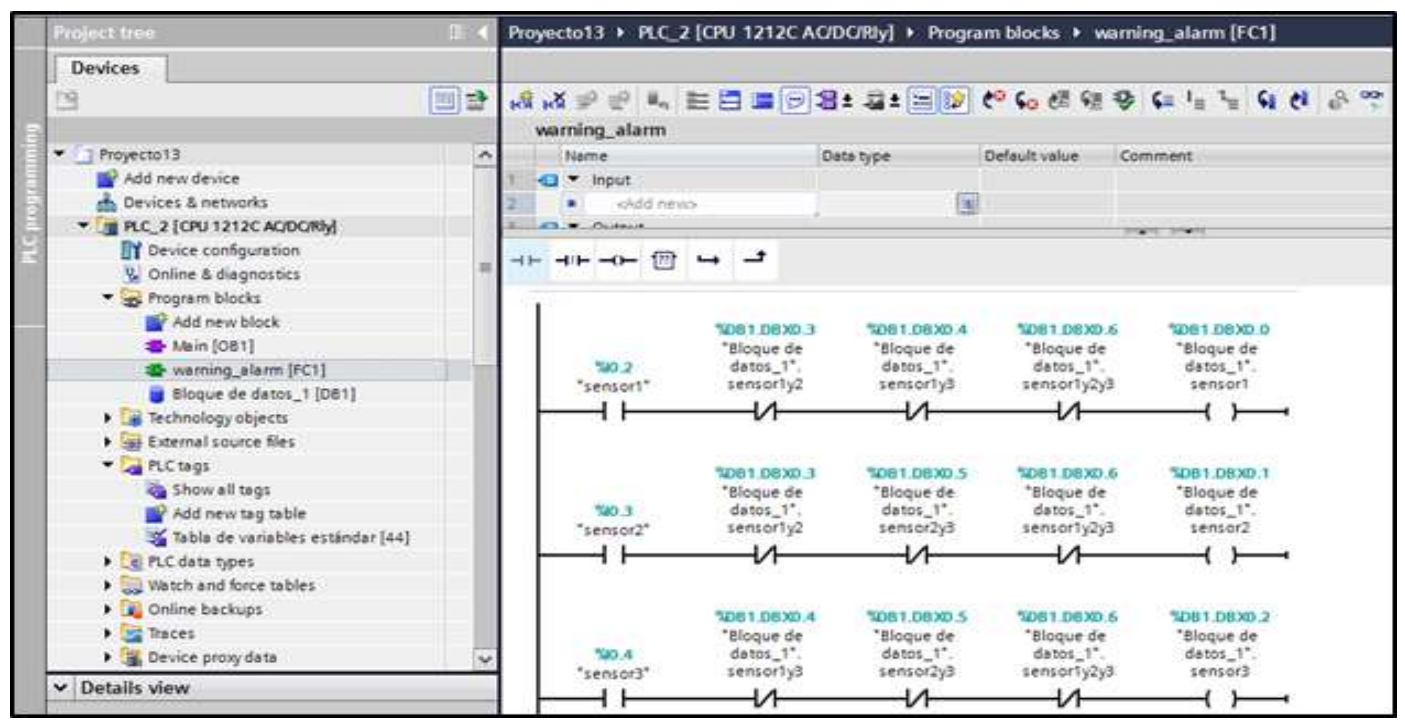

Figure 5. Programming the alarm history function block

Also in relation to the previous figure, in the function block in which the warning alarms are located, we see that in segment 2, sensor 1 (I0.2) and sensor 2 (I0.3) are in series with the data block_1 of sensors 1 and 2 and 3 (DB1.DBX0.6), which control the output of data block_1 of sensors 1 and 2 (DB1.DBX0.3). Sensor 2 (I0.3) and sensor 3 (I0.4) are in series with data block_1 of sensors 1 and 2 and 3 (DB1.DBX0.6), which control the output of data block_1 from sensors 2 and 3 (DB1.DBX0.5). Sensor 1 (I0.2) and sensor 3 (I0.4) are in series with data block_1 of sensors 1 and 2 and 3 (DB1.DBX0.6), which control the output of data block_1 from sensors 1 and 3 (DB1.DBX0.4). 
Regarding SCADA, an OPC (KEP SERVER EX6) will be used, which will integrate the PLC, hmi and computer. For this, a table of variables that are related to the PLC and that are in the OPC will be created in order to connect it with the Wonderware (INTOCH) to perform the SCADA. Figure 6 shows the programming for managing alarms in the InTouch, associated with the variables defined in the KepServerEX6.

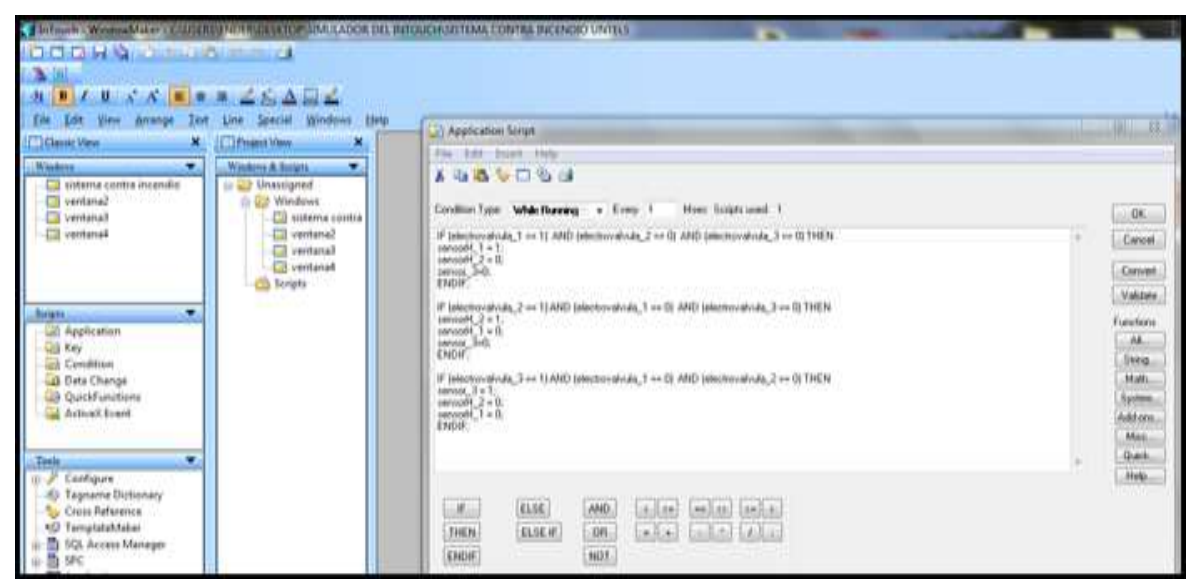

Figure 6. Programming the alarms on the InTouch

\section{RESEARCH METHOD}

\subsection{Research level}

The research carried out is descriptive, since it initially seeks to describe the operating conditions of an automated fire system using a programmable Logico controller, and for the purposes of monitoring and controlling its operation, a Supervision and Control (SCADA) system will be used). Descriptive research is what is used, as the name implies, to describe the reality of situations, events, people, groups or communities that are being addressed and that are intended to be analyzed [26].

Likewise, the research is correlational, since it will seek to determine the association level of the values monitored by the SCADA Supervision and Control system, in order to establish if these measured pressure and flow values are consistent with each other, thus validating the optimal performance of the fire fighting system. Correlational research is a type of non-experimental research method in which an investigator seeks to determine a degree of association between two variables [27]. Understand and evaluate the statistical relationship between them without influencing the behavior of any variable.

\subsection{Population and sample}

The population is made up of the only analysis unit that in this case is represented by the automated fire system using a Programmable Logic Controller; In this sense, by having a single analysis unit, the population will also be represented only by the Automated Fire System through PLC [28].

\subsection{Data collection}

The data will be collected through observation through annotations in technical reports, which will be obtained from the values provided by the same SCADA supervision and control system, which will be permanently monitoring the fire system and its operational indicators [29]. It is important to specify that the indicators to monitor are the pressure and flow of the Electric pump every time the sprinklers are activated.

\section{RESULTS AND DISCUSSION}

\subsection{Results}

Implemented the supervision and control system by SCADA for the automated fire fighting system, prototype level the following results were obtained. In a first test: when the warehouse sensor detected the fire, solenoid valve 1 was activated, with which the Water Pump operated at a low speed of $45 \mathrm{rpm}$ (revolutions per minute) and in the tank it can be observed that the pressure is 0.24 bar (pressure unit) and the tank level was quantified in 14 Liters, all the lighting system and outlet were turned off in order to avoid short circuits (the indicators light up in red), as shown in Figure 7. 
In a second test: when fire was generated in three zones, solenoid valve 1 , solenoid valve 2 and solenoid valve 3 were activated, with which the water pump operated at a high speed of $60 \mathrm{rpm}$ and in the tank the water level is 10.5 Liters, and the measured pressure turned out to be 0.6 bar, which is seen to increase when more solenoid valves are added; as shown in Figure 8.

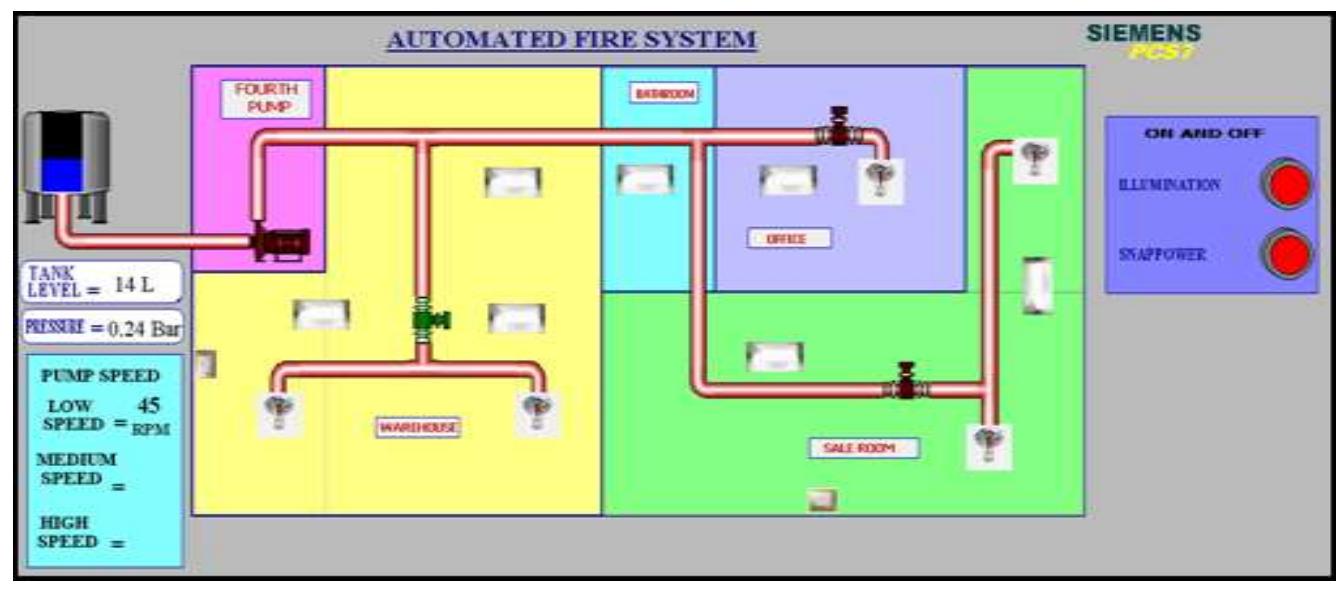

Figure 7. Result obtained from the pump pressure due to actuation of a solenoid valve

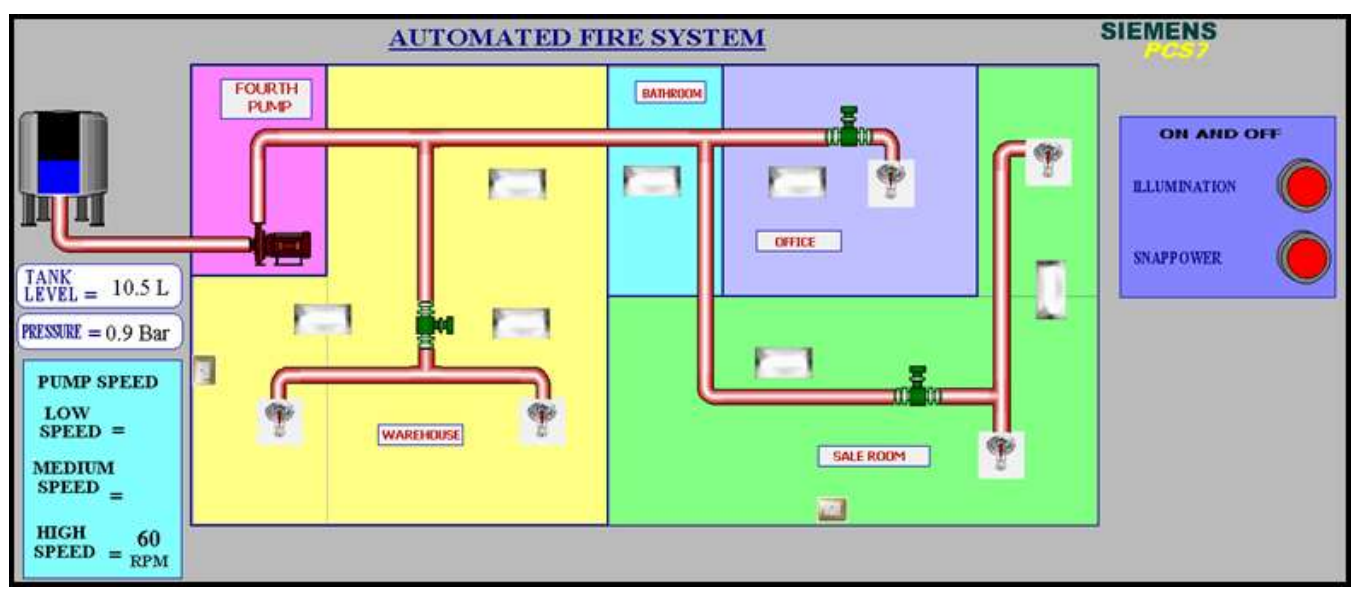

Figure 8. Result obtained from the pump pressure due to the actuation of three solenoid valves

Now in order to establish the level of correlation of the collected data, next I will perform the data processing for each scenario, using the Pearson's correlation coefficient, because the variables under study are of a quantitative type [30], for which the Spss V25 Statistics software will be used. Table 1 shows the highly significant correlation.

Table 1. Pearson correlation analysis result

\begin{tabular}{ccccc}
\hline & & Flow & $\begin{array}{c}\text { Pressure } \\
\text { (bar) }\end{array}$ \\
\hline Flow & Pearson & A powered sprayer & 1 & $0.977^{* *}$ \\
(liters/minute) & Correlation & Two powered sprinklers & 1 & $0.983^{* *}$ \\
& & Three powered sprinklers & 1 & $0.977^{* *}$ \\
Pressure & Pearson & A powered sprayer & $0.977^{* *}$ & 1 \\
(bar) & Correlation & Two powered sprinklers & $0.983^{* *}$ & 1 \\
& & Three powered sprinklers & $0.977^{* *}$ & 1 \\
\hline$* *$ The correlation is significant at the level 0.01 (bilateral).
\end{tabular}


Additionally, the dispersion model of the collected data (pressure and flow) is determined through the SCADA supervision and control system, in order to validate them. In this sense, the statistical software Spss V25 will be used. From Figure 9, it is shown that the model that best represents the behavior of the data collected in its three scenarios is the quadratic one; so also in Table 2, the determination coefficients $\mathrm{R}^{2}$, obtained from the Spss V25 Software, are shown for each of the scenarios analyzed.

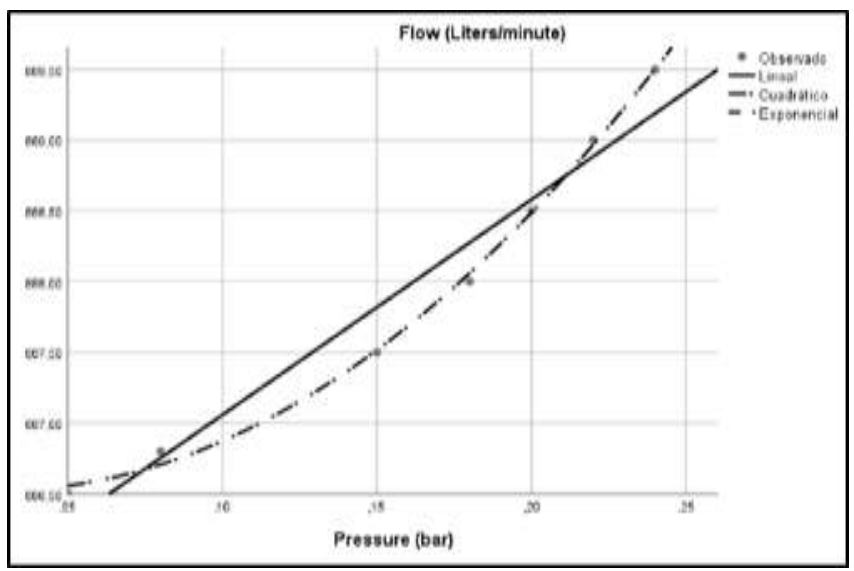

Table 2. Result of the $\mathrm{R}^{2}$ of other dispersion models analyzed

\begin{tabular}{ccc}
\hline \multirow{2}{*}{ Equation } & \multicolumn{2}{c}{ Model Summary } \\
& $\mathrm{R}^{2}$ & SIG. \\
\hline A powered sprayer & 0.988 & 0.000 \\
Two powered sprinklers & 0.999 & 0.000 \\
Three powered sprinklers & 0.999 & 0.000 \\
\hline
\end{tabular}

Figure 9. Dispersion model of the collected data

\subsection{Discussions}

In relation to the results obtained, and having carried out the correlation analysis and the dispersion model of the data obtained as part of the investigation. In relation to the objectives set as part of the investigation, the following discussions are detailed below:

In reference to the supervision and control of the operating parameters of a prototype fire fighting system, through a supervision and control system implemented through SCADA, it was possible to carry out the effective monitoring of the operating parameters such as pressure and flow. Achieving that there is a correlation between the variables under analysis, for the three scenarios proposed. In this sense, in the investigation carried out by Rodriguez (2018), he points out that the SCADA system allowed monitoring the pressure and flow parameters of a fire-fighting system, guaranteeing its operation, achieving a correlation of its significant level variables [31].

Referring to the dispersion model that describes the behavior of the collected data such as pressure and flow, it was found that in all three scenarios the model that best represents the quadratic model; in this regard in the thesis related by Naranjo and Salazar (2016), a sign that the design and implementation of the SCADA system allowed to monitor the pressure and flow rate of the system against fire, achieving to determine that the behavior of said variables was of exponential type [32]. In this regard, this result could be discussed because the control or regulation is not carried out through a frequency inverter but on the contrary, they implement an Integrative and derivative proportional controller in the PLC; which does not allow to achieve a better precision in the regulation of pressure and flow.

\section{CONCLUSION}

It is concluded that it managed to monitor and supervise the operating parameters such as pressure and flow of a prototype fire fighting system, through a supervision and control system implemented through SCADA, using the OPC KepServerEX6, which allowed the integration of the PLC, the human-machine interface and the computer, ensuring that the monitored results for both pressure and flow are consistent and reliable; It was possible to determine the level of correlation between the indicators to be monitored by the SCADA system, under three scenarios, that is, when the drive is in a single sprinkler, or in two sprinklers or in three sprinklers, a correlation level was obtained as a result. Highly significant equal to $0.977,0.983$ and 0.997 respectively.

Finally, it is concluded that it was possible to determine the dispersion model of the indicators monitored by the SCADA system (pressure and flow), making an analysis of various dispersion models, such as the linear, quadratic and exponential models using their determination fator, obtaining that the model that 
best represents the behavior in the three cases is the quadratic dispersion model, with an average determination factor of 0.99 in the three scenarios experienced.

\section{ACKNOWLEDGEMENTS}

The authors wish to recognize and thank the National Technological University of South Lima for their support of this investigation.

\section{REFERENCES}

[1] L. Orbe, "Analysis of Risks oriented to fires and proposal for improvement to be taken in the facilities of district 17D07 under the Ministry of Health," M.S.thesis, University of the Americas, Quito, Ecuador, 2017.

[2] F. Fernández and J. Duarte, "Automation for monitoring and control of a group generator with electric start," Engineering and Technology Magazine, pp. 262-271, 2017.

[3] M. Poblete, et al., "Comprehensive system of supervision and control of occupational safety facilities in a UCO department building," Granada Conference Center, España, XV Adaluz Congress of Occupational Safety and Health, pp. 47-56, 2015.

[4] A. Hahnemann, et al., "Fire safety evaluation: Alternative method applied to Brazilian Buildings," Magazine of the Latin American Association for Quality Control, Pathology and Recovery of Construction, pp. 186-199, 2017.

[5] D. Carrero, "Design of a Supervisory Control and Data Acquisition System (SCADA) for remote monitoring of Energy systems," M.S.thesis, University of Carabobo, Valencia, Venezuela, 2018.

[6] I. Antesana and A. Medina, "Edificis B.M.S Centralized Contreol System," M.S.thesis, Catholic University of Cordoba, Cordoba, Argentina, 2016.

[7] O. Ruiz, "Hydraulic fire protection systems, Design, Construction, Operation and Maintenance," M.S.thesis, Colombian School of Engineering Julio Garavito, Bogota, Colombia, 2016.

[8] G. Vargas, "Design and Description of an Automated Fire Protection System on a 45 meter yacht from Length," M.S. thesis, Catholic University of Santiago de Guayaquil, Guayaquil, Ecuador, 2016.

[9] L. García and E. Villarreal, "Implementation of a SCADA system for the automation of a biotechnology laboratory of biological safety level," Scientific threshold, vol. 14, pp. 119-129, 2018.

[10] J. Romero, "Control and Protection System against Fires for the General Hospital of Macas in the Province of Morona Santiago," M.S.thesis, Technical University of Ambato, Ambato, Ecuador, 2017.

[11] E. Cabrera and A. Aloma, "Fire Protection System for the Oil Industry," Journal Hydraulic and Environmental Engineering, pp. 33-47, 2016.

[12] J. Poma, et al., "Design, construction and implementation of an automated integrating system for flow, pressure and temperature modules of the advanced manufacturing center," Journal Systems and computing, pp. 90-95, 2017.

[13] J. Flores, "Supervision, Control and Integration by PLC of a Process that Simulates the Selection and Drilling of Parts," M.S. thesis, Polytechnic University of Catalonia, Catalunya, España, 2017.

[14] R. Andrade, "Teaching module to control water level and flow using SCADA system, PLC and PID algorithm," Journal RIEMAT, vol. 4, pp. 50-62, 2018.

[15] G. Sánchez and A. Custodio, "Development of SCADA system for flow control based on LINUX," University, Science and Technology, vol. 11, no. 44, pp. 121-128, 2017.

[16] G. Zapata, et al., "Aportes Metodológicos para el Diseño de Sistemas de Supervisión de Procesos Continuos," Journal Technological information, vol. 22, no. 3, pp. 97-114, 2010.

[17] E. Lopez, "SCADA Systems in Industrial Automation," Journal Technology in Progress, pp. 3-14, 2017.

[18] L. Barzaga, et al., "SCADA Systems for the Automation of CIGB Production Processes," Journal Electronic Engineering, Automation and Communications, pp. 20-37, 2016.

[19] A. Rodríguez, et al., "Synchronization and Integration in SCADA of a process desalination," Journal Electronic Engineering, Automation and Communications, pp. 334-354, 2019.

[20] M. Ruiz, "Design of a SCADA module for practical teaching with Profibus communication and S7-1200 PLC's for the laboratory of the School of Electronic Engineering of the UNP," M.S.thesis, National University of Piura, Piura, Perú, 2016.

[21] J. Aguinsaca and C. Miranda, "Modeling and Monitoring of the Electrical System of the CT2 Transformation Chamber," M.S.thesis, University of the Armed Forces, Latacunga, Ecuador, 2016.

[22] J. Quezada, et al., "Design and implementation of a control and monitoring system based on HMI-PLC for a drinking water well," Engineering, research and technology, vol. 15, no. 1, pp. 41-50, 2018.

[23] I. Silipú, "Design of a SCADA System using Wonderware System Platform for monitoring the Electric Interconnected of Lot $1 \mathrm{AB}$ of PlusPetrol," M.S.thesis, Pedro Ruiz Gallo National University, Lambayeque, Perú, 2016.

[24] W. Ramos, "Design of a Semiautomatic Control using PLC s7-200 with SCADA Interface of a Biological Sludge Water Treatment Plant," M.S.thesis, National University of the Altiplano, Puno, Perú, 2016.

[25] J. Molano and L. Rodriguez, "Design of the Fire Fighting and Detection system for the Technological faculty of the Francisco José Caldas District University," M.S.thesis, Francisco José Caldas District University, Bogota, Colombia, 2017.

[26] C. Bernal, "Investigation methodology," Pearson Education, 2016.

[27] F. Arias, "The Research Project," Sexta Edición, Mexico D.F, Mexico, Episteme, 2016. 
[28] O. Atalaya, "Fire System for an Automated Electrical Substation via Programmable Logic Controller," Advances in Science, Technology and Engineering Systems Journal, vol. 4, no. 6, pp. 353-359, 2019.

[29] R. Hernandez, "Investigation methodology," Décima Edición, Mexico D.F, Mexico, Mc Graw Hill, 2016.

[30] A. Hernández, et al., "Cientific investigation methodology," Alicante: Ed. Innovation and Development Area, 2018.

[31] N. Rodriguez, "SCADA design to monitor fire alarms at the Lambayeque Chiclayo Regional Hospital," M.S.thesis, Cesar Vallejo University, Chiclayo, Perú, 2018.

[32] C. Naranjo and C. Salazar, "Design and implementation of a SCADA for the Supervision and Automatic Control of the Fire System,” M.S.thesis, Salesina Polytechnic University of Quito, Quito, Ecuador, 2016.

\section{BIOGRAPHIES OF AUTHORS}

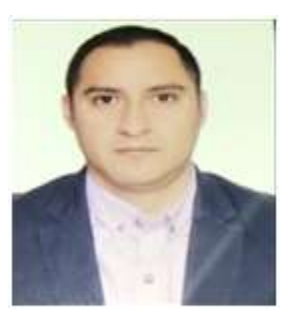

Omar Freddy Chamorro Atalaya is Electronic engineer, school and enabled with master's degree in systems engineering. Master teacher in the industrial automation course. Professional experience in industrial network automation projects in drinking water systems. Author of several scientific articles in journals indexed in Scopus, in different areas, such as: Supervision and Process Control, Industrial Automation, Solar Panels and Automation of Fire Systems.

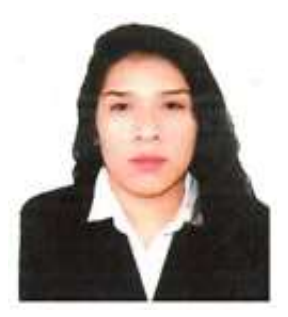

Dora Yvonne Arce Santillan is graduated in electrician mechanical engineer at the National Technological University of Lima Sur, colleged and enabled. With studies of Master in Electrical Engineering with mention in Project Management. Author of several scientific articles in journals indexed in Scopus, in different areas, such as: Supervision and Process Control, Industrial Automation, Solar Panels, Automation of Fire Systems and Behavioral Sciences.

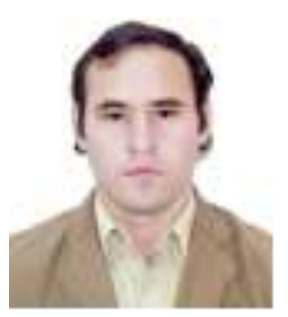

Teodoro Neri Diaz Leyva. He holds a Master's Degree in Systems Engineering, Professional Title of Systems Engineer from the Federico Villarreal National University. He teaches at the National Technological University of Lima Sur, specialized in Programming Languages, Database, Software Engineering and Artificial Intelligence.

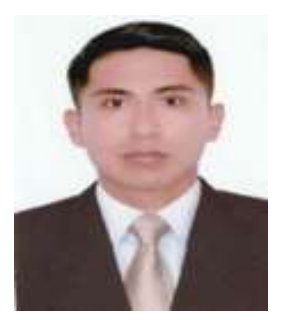

Martín Diaz Choque is is graduated electrician mechanical engineer at the National Technological University of Lima Sur. Author of several scientific articles in journals indexed in Scopus, in different areas, such as: Supervision and Process Control, Industrial Automation, Solar Panels, Automation of Fire Systems and Behavioral Sciences. 